\begin{tabular}{|c|c|}
\hline \multirow{3}{*}{ 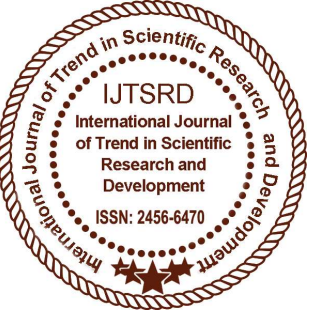 } & $\begin{array}{l}\text { International Journal of Trend in Scientific } \\
\text { Research and Development (IJTSRD) }\end{array}$ \\
\hline & International Open Access Journal \\
\hline & ISSN No: 2456 - 6470 | www.ijtsrd.com | Volume - 1 | Issue - 6 \\
\hline
\end{tabular}

\title{
Perceived Distress, Depressive Symptoms and Health - related Quality of Life of Breast Cancer Survivors
}

\author{
Mrs. Gigi Thomas \\ Research Scholar, MAHER University, Chennai \\ Dr R. Shankar Shanmugam \\ Coordinator Nursing Education \& \\ PME/Sr.Nursing Tutor, Tamilnadu Govt Multi \\ Super Specialty Hospital, Chennai-2
}

\begin{abstract}
Mrs. P. Vanaja
Academic officer/Nursing Tutor, Coordinator-

Nursing Education \& PME, Tamilnadu Govt

Multi Super Specialty hospital, Chennai-3
\end{abstract}

Prof. Dr. E.Prabhu

HOD, Institute Nuclear \& Molecular Imaging, Tamilnadu Govt Multi Super Specialty hospital, Chennai-3

\section{ABSTRACT}

Aim: The aim of the study was to assess the level of Perceived Distress, Depression and Health-related Quality of life(QOL) of Breast cancer survivors. Methods: A descriptive study design was adopted. The participants of 100 were selected, by convenient sampling technique. The Structured interview schedule was used to collect the data from samples by using Distress screening tool, Zung Self-Rating Depression Scale (SDS) and Cancer Health related Quality of life scale. Results: Among 100 samples, the majority (40\%) were in the age group of 31-50 yrs and only $8 \%$ in age group of $21-30$ yrs. $12 \%$ of breast cancer survivors have no perceived Distress where as $88 \%$ of them have Severe Distress. $58 \%$ of them had mild depression, $20 \%$ has moderate depression and $10 \%$ has severe depression. $34 \%$ of the breast cancer survivors have moderate QOL,66 \% has good QOL. there was a positive fair correlation between the Distress and Quality of Life among Breast cancer survivours. There was a negative fair correlation between Distress and Quality of life $(p=0.01)$.Similarly, There was a negative fair correlation between Depression and Quality of life $\operatorname{scale}(p=0.01)$.All these data are statistically significant. Conclusion: Majority have Perceived Distress, Depression and moderate to good Health

related Quality of life. Adequate intervention to be given to address the Distress, Depression and Health related Quality of life

Keywords: Perceived Distress, Depression, Health related quality of life, Breast cancer Survivors

\section{INTRODUCTION:}

The diagnosis and management of Breast cancer have the great impact on women's physical, Psychological and spiritual well being balancing their Quality of life. According to WHO (2017), Cancer causes significant mortality and morbidity among women with approximately 14 million new cases in 2012 . The number of new cases is expected to rise by about $70 \%$ over the next 2 decades. Cancer is the second leading cause of death globally, and was responsible for 8.8 million deaths in 2015. Globally nearly 1 in 6 deaths is due to cancer Advanced treatment in Breast cancer among women can extend the survival time. Breast cancer remains a prevalent and Distressful experience for hundreds of thousands of women each year around the world. DiDistress and Depression has a strong and complex relationship with Breast cancer.

Depression has been associated with disease severity, level of patient disability, Physical improvement, the poor performance of status and survival. It is scientifically proved that depression is a major source 
of Distress and can have a greater impact on Quality of life Breast cancer survivors.

Understanding the epidemiology of depression, Distress and its adverse impact on quality of life during survival period have a high clinical and public health significance. Studies show the significant impact of depression and depressive symptom are well beyond the treatment phase of Breast cancer.

\section{Background and Need for the Study:}

Worldwide, Cancer accounts for 8.8 million deaths in 2015 and it is the leading cause of death. The Breast cancer is the most common causes of cancer death (WHO,2016).The survival rates of women with Breast cancer are expected to be superior to 15 years and are $95 \%$ of those with localized disease will survive additional 5 years or more.

Though the evaluation of cancer therapies has historically focused on biomedical measures, there has been an increasing interest in determining the disease and its impact on Health- related Quality of life (HRQOL).Recent investigations also indicated the Psychological variables play a major role in predicting HRQOL.

There are few studies addressing Psychological perspective such as Depression and Distress on Cancer in India. Taking the above account, the aim of the study is mainly descriptive and explorative. In the present work, we focus on describing the characteristics of Distress and depression and HRQOL and examine the association between these variables with HRQOL as main outcome. The number of Cancer survivors and people with cancer symptoms under control is increasing and therefore the research in their quality of life increases more and more importance as well. An important role for nurses is to provide support to promote Psychological health and QOL of the Breast Cancer Survivors.

\section{Statement of Problem}

A study to assess the level of Perceived Distress, Depressive symptoms and HRQOL of breast cancer survivors attending Oncology Department in a tertiary care setting.

\section{Objectives}

1. To assess the perceived Distress ,depressive symptoms and HRQOL among breast cancer survivors
2. To correlate the level of perceived Distress, depressive symptoms with quality of life of breast cancer survivors

3. To associate the demographic variables with perceived Distress, depressive symptoms \& quality of life of breast cancer survivors

\section{Materials and Methods}

The necessary Permission was obtained to conduct this study. A convenient sampling technique was employed to select a hundred samples from Oncology outpatient clinic, TamilNadu Government Multi Super Specialty Hospital, Chennai-02.Informed consent were obtained from the participants. The structured interview method was used to collect data from the participants of 10-15 minutes without having any possible interaction with other participants. Perceived Distress, Depression and Health related Quality of life scale were assessed by using Distress screening tool, Zung Self-Rating Depression Scale (SDS) and Cancer Health related Quality of life scale. Perceived Distress was interpreted as -- $0=$ no distress, $10=$ extreme distress $\&>4$ requiring intervention. The QOL was scored as 0-3 -Poor QOL, 4-5 Moderate QOL, 6-8 Good QOL, 9 -10 Very Good QOL.

\section{CRITERIA FOR THE SELECTION OF SAMPLES:}

\section{Inclusion criteria:}

Breast cancer Survivors, who are,

Attending Oncology clinic for treatment

Only women clients

know the language of Tamil or English

Willing to participate in the study

\section{Exclusion Criteria:}

Breast cancer Survivors, who are,

Don't know the language of Tamil or English

Not willing to participate in the study.

Bed ridden clients.

\section{Results:}

The collected data were analyzed by using descriptive $\&$ inferential statistics and tabulated as follows. 
Table 1: DEMOGRAPHIC VARIABLES:

Among 100 samples, the majorities (40\%) were in the age group of $31-50 \mathrm{yrs}$ and only $8 \%$ in age group of 21-30 yrs. regarding marriage, the maximum level of $68 \%$ were married and only $2 \%$ were single/unmarried. The majority $(62 \%)$ of them were belongs to Hindu and 58\% had school level education. Nearly half of the caregivers $(55 \%)$ were belongs to nuclear family and $47 \%$ of type of caregivers were mostly spouse. The majority $(79 \%)$ of the cancer survivors were attended some forms of school and $21 \%$ were not having any non formal education. Considering about residential area, the majority (86\%) were from residing at urban, Semi urban areas and $14 \%$ were from rural areas. $14 \%$ were had the family history of Cancer. $49 \%$ of the cancer survivors has the co-morbidity disease conditions such as Hypertension, Dyslipidemia, Diabetes and heart diseases. $77 \%$ of them were receiving Surgical, Radiation and Chemotherapy and remaining were receiving any one of the treatment. Based on BMI, 7\% underweight, $30 \%$ Normal weight, $53 \%$ obese and 105 over weight

Table 1: Level of perceived Distress score among breast cancer survivors

Distress interpretation -- $0=$ no Distress, 10 $=$ extreme, Distress $>4$ requiring intervention

\begin{tabular}{|l|l|l|}
\hline $\begin{array}{l}\text { Level of } \\
\text { Perceived } \\
\text { Distress }\end{array}$ & No. of patients & $\%$ of patients \\
\hline$\leq 4$ & 12 & $12.0 \%$ \\
\hline $\mathbf{3}$ & 88 & $88.0 \%$ \\
\hline
\end{tabular}

Table 1 showed that $12 \%$ of breast cancer survivors has no perceived Distress where as $88 \%$ of them has Severe Distress that requires immediate intervention. The mean Distress is 7.2 and the standard Deviation is 1.69 .

\section{Table 2: LEVEL OF SELF-RATING DEPRESSION SCALE SCORE}

\begin{tabular}{|c|c|c|}
\hline $\begin{array}{ll}\text { Level } & \text { of } \\
\text { depression } & \end{array}$ & No .of patients & $\%$ \\
\hline Normal & 12 & $12.0 \%$ \\
\hline Mild & 58 & $58.0 \%$ \\
\hline Moderate & 20 & $20.0 \%$ \\
\hline Severe & 10 & $10.0 \%$ \\
\hline Total & 100 & $100.0 \%$ \\
\hline
\end{tabular}

Table 2 showed that Among 100 Breast cancer survivours, $58 \%$ of them had mild depression, 20\% has moderate depression and $10 \%$ has severe depression

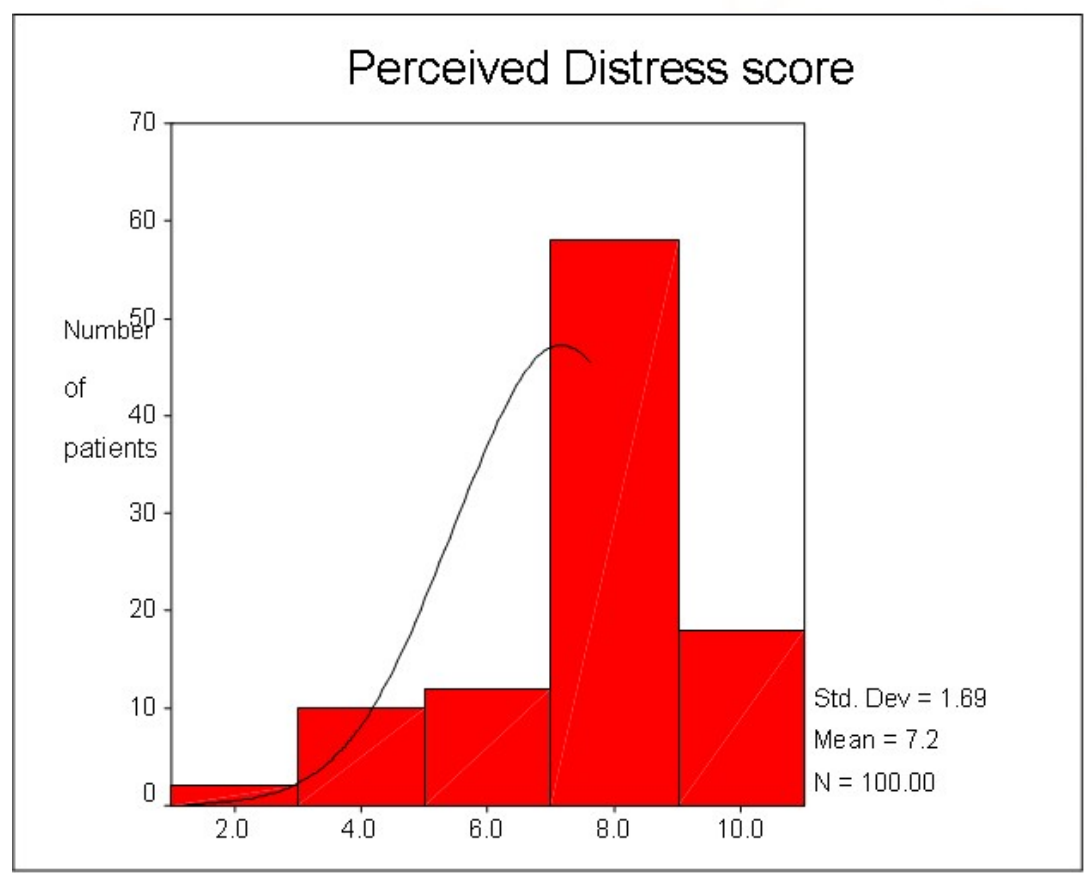

Fig1: Histogram with normal curve shows the distribution of Perceived Distress score among breast cancer survivors. 
International Journal of Trend in Scientific Research and Development (IJTSRD) ISSN: 2456-6470

Table 3: LEVEL OF QUALITY OF LIFE OL- CANCER SURVIVOR SCALE SCORE

\begin{tabular}{|c|c|c|}
\hline Level of QOL & No .of patients & $\%$ \\
\hline Poor & 0 & $\mathbf{0 . 0} \%$ \\
\hline Moderate & 34 & $34.0 \%$ \\
\hline Good & 66 & $66.0 \%$ \\
\hline Very good & 0 & $0.0 \%$ \\
\hline Total & 100 & $100.0 \%$ \\
\hline
\end{tabular}

Min score $=0$ Maxi score $=10$

Table 3 showed the level of QOL-CS scale score, 34\% has moderate QOL,66 \% has good QOL.

Table 4: Correlation between Perceived Distress, Self rating depressive scale (SDS) and quality of life (QOL) score among breast cancer survivors.

\begin{tabular}{|c|c|c|c|}
\hline $\begin{array}{l}\text { Correlation } \\
\text { between }\end{array}$ & $\operatorname{Mean} \pm$ SD & $\begin{array}{l}\text { Karl Pearson } \\
\text { correlation } \\
\text { coefficient }\end{array}$ & Correlation interpretation \\
\hline $\begin{array}{l}\text { Perceived Distress } \\
\text { Score } \\
\text { vs } \\
\text { SDS }\end{array}$ & $\begin{array}{l}7.16 \pm 1.69 \\
\text { Vs } \\
45.17 \pm 5.76\end{array}$ & $\mathrm{r}=0.33 \mathrm{p}=0.01$ & $\begin{array}{l}\text { There is a positive fair correlation between } \\
\text { Distress score and SDS score. It means } \\
\text { Distress score decreases their SDS score also } \\
\text { decreases. }\end{array}$ \\
\hline $\begin{array}{c}\text { Perceived Distress } \\
\text { score } \\
\text { Vs } \\
\text { QOL }\end{array}$ & $\begin{array}{l}7.16 \pm 1.69 \\
\text { Vs } \\
5.42 \pm 0.88\end{array}$ & $\mathrm{r}=-0.38 \mathrm{p}=0.01$ & $\begin{array}{l}\text { There is a negative fair correlation between } \\
\text { Distress score and SDS score. It means } \\
\text { Distress score decreases their QOL score } \\
\text { increases }\end{array}$ \\
\hline $\begin{array}{c}\text { SDS } \\
\text { Vs } \\
\text { QOL }\end{array}$ & $\begin{array}{l}45.17 \pm 5.76 \\
\text { Vs } \\
5.42 \pm 0.88\end{array}$ & $\mathrm{r}=-0.40 \mathrm{p}=0.01$ & $\begin{array}{l}\text { There is a negative fair correlation between } \\
\text { SDS and QOL score. It means QOL score } \\
\text { decreases their QOL score increases. }\end{array}$ \\
\hline
\end{tabular}

\section{Interpretation for r-value}

Pearson correlation coefficient is denoted by " $\mathrm{r}$ " " $\mathrm{r}$ " always lies between -1 to +1

$0.0-0.2$ poor correlation

$0.2-0.4$ fair correlation

$0.4-0.6$ moderate correlation

$0.6-0.8$ substantial correlation

$0.8-1.0$ strong correlation
Table 4 showed that there was a positive fair correlation between the Distress and Quality of Life among Breast cancer survivours. There is a negative fair correlation between Distress and Quality of life $(p=0.01)$.Similarly, There was a negative fair correlation between Depression and Quality of life $\operatorname{scale}(p=0.01)$.All these data are statistically significant. 
Association between Level of Perceived Distress score and Demographic variables

The Association between Level of Perceived Distress score and Demographic variables showed that the Age (elders), Education (less educated), income(less income) and Family history of cancer

(Yes) are having more level of Distress score than others. Statistical significance was calculated using chi square test. ( $\mathrm{P}=0.05)$.

\section{Association between Level of self-rating depression score and Demographic variables}

The Association between Level of self-rating depression score and Demographic variables showed that the Age (elder), Education (less educated), income (less income) and BMI (overweight/obese) women are having more level of self-rating depression score than others. Statistical significance was calculated using chi square test. $(p<0.01)$.

\section{Association between Level of QOL score and Demographic variables}

The Association between Level of QOL-CS score and Demographic variables showed that Age (Younger), Education (more educated), income (more income) and place of residence ( urban) are having more level of quality of life than others. Statistical significance was calculated using chi square test $(p<0.01)$.

\section{Discussion:}

This Study found that Majority ( $88 \%$ ) of breast cancer survivors has increased Perceived Distress Score (Mean 7.2,SD=1.69),Elderly clients, less educated, less Income and family history of cancer are having more Distress score and it is statistically significant $(\mathrm{P}=0.01)$. The above findings were supported by the study conducted by Yingchun Li et al (2015) and found breast cancer patients usually suffer from incredible Distress while under active treatment and there is positive correlation with depressive symptoms. Women with breast cancer had greater social and interpersonal Distress.

The results also showed that majority (88\%) of cancer survivors have Mild to moderate depression. The elderly age, less educated less Income and BMI (Over weight / Obese). Women are having Increased depression score and it is statistically significant $(\mathrm{P}=0.01)$. the above result were supported by study by Ju-Yu Yen ut (2006) and found Majority (60\%) of the Breast Cancer survivours were suffering from depression and Economic Distress (Income). Hall et al evaluated breast cancer patient's depression and $3.7 .2 \%$ of the patients were depressed after Operation. This Prevalence of depression is higher than the prevalence rate in general population of $17 \%$ and 20 $25 \%$ in women with cancer. These results showed that the cancer survivors have heavier Psychological difficulty under active treatment after diagnosis of cancer.

The Majority $(90 \%)$ of the Cancer survivors are having moderate to good Quality of Life .The younger age, highly educated, having good Income and living in urban area breast cancer survivors are having increased level of QOL than others and it is statistically significant $(\mathrm{p}=0.01)$.

It is also found that there is a positive fair correlation between Perceived Distress score and Depression (SDS) Score $(p=0.01)$.There is also negative fair correlation between perceived Distress score and QOL $(p=0.01)$.Similarly, there is a negative fair correlation between SDS score and the QOL score $(\mathrm{p}=0.01)$. The above findings were supported by the study conducted by McDonald Mu et al (1999).

\section{CONCLUSION:}

The Present study provides the information about the level of perceived Distress, Depression and Quality of Life (QOL) of Breast cancer survivors. It also provided the information on the association between the domains such as perceived Distress, Depression and Quality of life. Clients with breast cancer have more Distress, severe depression and moderate to good Quality of life. It is necessary to develop strategy to reduce the severe Distress and depression, so that majority of the breast cancer survivor will move on to Good Quality of life and they can lead a positive productive life.

\section{REFERENCES:}

1) Daniel L, et al. "Relationship between sleep problems and psychological outcomes in adolescent and young adult cancer survivors and controls", Support Care Cancer; 2015; 1-8.

2) Zhe Lou et al, Affects of Anxiety and Depression on Health-Related Quality of Life among patients with Benign Breast Lumps Diagnosis via Ultrasonography in China, Int $\mathrm{J}$ Environ Res Public Health: 2015; 12, 10587-10601.

3) Micaela Reich \& Eduardo Remor, "Psychological Variables Associated with Health Related Quality of Life in Uruguayan surgically intervened for 
Breast Cancer", Psychology, Community \& Health:2014,Vol 3(3),172-188.

4) Hong JS, Tian J, "Prevalence of anxiety and depression and their risk factors in Chinese cancer patients. Supportive Care in Cancer", 2014; 22(2): 453-459.

5) Yingchun Li et al ," The Mediating role of Mental adjustment in relationship between perceived Distress and Depressive symptoms in Hematological cancer patients: A cross sectional study,PLOS one; (2014) 10(11).

6) Ju-yu-yen et al, Quality of life, depression, and Distress in breast cancer women outpatients receiving active therapy in Taiwan, Psychiatry and Clinical Neurosciences (2006), 60, 147-153.

7) McDonald MV, et al,'Nurses' recognition of depression in their patients with cancer", Oncol. Nurs.Forum 1999; 26: 593-599.

8) Hall A, A'Hern R, Fallowfield L. Are we using appropriate self-report questionnaires for detecting anxiety and depression in women with early breast cancer. Eur. J. Cancer: 1999; 35: 79-85. 